Можно также производить расчет параметров предельных детонационных режимов, таких как спин (см Рис. 10) и «галоп».

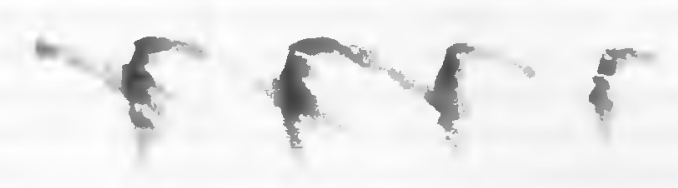

Рис. 10 - Фотог рафия головы детонационног спииа

Обратно пропорциональная зависимость размера детонационной ячейки от давления исходной горючей смеси позволяет управлять детонационным процессом, что немаловажно для решения практических проблем взрывобезогиасности $[2,4,11]$.

Онисанные выше программные комплексы является составной частью интеллектуальной системы поддержки принятия решений (ИСІІІ IP) по вопросам детонации конденсированных и газовых систем.

\title{
Литература
}

1. Щелкин К.И., Трошин Я К Іазодинамика горения. - М.: Изд-во АН СССР. - 1963. - 256с

2. Зверев И.Н., Смирнов Н.Н. Газодинамика горения. - М.: Изд-во МГУ. - 1987 - 307с.

3. Взрывные явления. Оценка и последствия: В 2-х кн. Кн.1 / Бейкер У., Кокс ІІ., Уэстайн П. и др. - М: Мир, 1986. $-319 \mathrm{c}$.

4. Нетлетон М. Детонация в газах. - М.: Мир - 1989. - 280с.

5. Јандау Л.Д., Лифшиц Е.М. Теоретическая физика. В 10 т. : Т. VI Гидродинамика. - М.: Наука. Гл. ред. физ.-мат. лит.- 1986. - $736 \mathrm{c.}$

6. Нигматулин Р.И. Динамика многофазных сред. Ч.1. - М: Гл. ред. Физ.-мат, лит. $1987 .-464 \mathrm{c}$.

7. Мейдер Ч Численное моделирование детонации. - М:Мир.- 1985.-384c.

8. Црёмин А.Н., Савров С.Д., Трофимов В.С., ІІведов К.К Цетонационные волны в конденсированных средах. - М.: Наука - 1970. -163с.

9. Коробейников В.П. Задачи теории точечного взрыва. - М.: Наука. Гл. ред. физ.-мат. лит., $1985 .-400$ с

10. Волков В.Э. Пределы детонации и проблемы взрывобезопасности. - Гаукові праці Одеської національної академії харчових технологій. - Одеса, 2006. - Вип. 28 - С. 194-199.

11. Асланов С.К., Волков В.Э., Царенко А.П. Математический анализ структуры детонационных волн в различных средах. // Вестник ОГУ. -1999.-Т.4.Вып 4. Физ.-мат.науки.- С.134.

12. Асланов С.К. Критерий неустойчивости детонации Чепмена-Жуге в газе. // Доклады АН СССР. -1965. Т. 163. №3-С.667.

13. Канель Г.И., Дрёмин А.Н. Разложение литого тротила в ударных волнах. // Физика горения и взрыва.-1977. Т.13.- №1. С. 85 .

14 Оран Э., Борис Дж. Численное моделирование реагируюших потоков. - М:Мир.- 1990-660с.

15. Мазмишвили А.И. Способ наименьших квадратов. - М.: Недра, 1968. - 440 с.

\section{РЕАЛИЗАЦИЯ ЗАДАЧИ ОЦЕНИВАНИЯ ПОКАЗАТЕЛЕЙ РАБОТЫ ЗАВОДА В АСУТП САХАРНОГО ПРОИЗВОДСТВА}

\section{Жуковский Э.И., докт. техн. наук, Скаковский Ю.М., канд. техн. наук, Витвицкий В.Д., Бабков А.В. Одесская национальная академия пищевых технологий}

Рассиатриваются вопросы реализации подсистеиы оперативиого учета основиых показателей работы сахарного завода. Подсистена функиионирует в составе АСУТП свеклосахарного производства.

The questions of realization of operative account subsystem basic indexes of sugar plant work are examined. A subsystent operates in computer system structure of sugar-beet production. 
Ключевые слова: системы автоматизации, оперативный учет, основные цоказатели, алгоритм, технологический участок, свеклосахарное производство.

\section{Введение}

В составе АСУТП крупных предіриятий пищевой промышленности помимо традиционных задач контроля и управления разрабатываются информационные подсистемы, обеспечиваюшие технических руководителей дополнитеьной оперативной информацией о характере протекающих технологических процессов, состоянии оборудования, качестве управления процессами, показателях эффективности работы и т. п. [1, 2, 3]

На сахарных заводах в составе АСУТП свеклосахарного производства предлагается реализовать подсистему оперативного учета и представления основных технико-экономических показателей $[1,4]$, которая обеспечивает представление результатов расчетов на различных уровнях управления (АРМах) для диспетчера (начальника смены), главного инженера, главного технолога, директора и т.и.

1Іри необходимости, экранные формы, таблицы, графики и г. п., могут быть выведены на принтер и сведены в архивы бумажных документов.

Традиционые критерии управления заводом, принятые в производстве сахара, при их наглядной интерпретации могут быть полезными не только при анализе успешности функционирования предприятия за сутки, декаду, месяц, но и при текущем анализе внутрисменной работы.

Іредставляемые данныс используются техническими руководителями завода для оперативного контроля, анализа и своевременного принятия решений по управлению технологическими процессами свеклосахарного производства (корректировки режимов, производительности и т п.), оценки работы отдельных смен и завода в целом.

ІІодобные корректировки позволят минимизировать удельные затраты ресурсов, в том числе расхода газа, электроэнергии, потребляемой из городской сети, свежей воды, пара и тепла (с паром), передаваемые на выпарную станцию (ВС) из ТЭІ, при выпуске готовой продукции требуемого качества

\section{Основные технические решения}

В Одесской национальной академии пишевых технологий совместно с НІО «Іищепромавтоматика» (г. Одесса) проводятся работы по разработке и внедрению АСУТП на ряде сахарных заводов Украины.

В составе вновь разрабатываемых АСУТП предлагается создание пгодсистемы оперативного учета и представления основных технико-экономических показателей работы завода, структура которой представлена на рис. 1 .

В блоке 1 осуществляется контроль текущих значений параметров от датчиков, их предварительная обработка (проверка достоверности, фильтрашия, масшгтабирование и т. п.) для передачи в блоки 2 и 3.

В блоке 2 осуществляется вычисление показателей в соответствии с расчетными формулами приведенными в [1], дия передачи результатов в блок 4, где осуществляется представление их на АРМ технических руководителей. Показатели, рассчитываемые в блоке 2, представляют собой уделыные затраты ресурсов на производство: газа, свежей воды, пара и тепла из ТЭЦ и г.П. Резултаты представляются в виде динамических графиков изменения показателей в течение смены и помогают, в случае их ухудшения, своевременно вносить коррекцию в режимы работы. В блоке 3 производят посменное интегрирование расходов основных ресурсов, затрачиваемьх на производство, результаты расчетов сводится в таблицу, вызываемую по желанию конечным пользователем [1].

Экранная форма представления результатов полученных в блоках 2 и 3 приведена на рис. 2, на примере АРМ главного инженера. Удельные показатели, рассматриваемые в подсистеме, определяются делением предварительно обработанньгх сигналов расходов ресурсов на расход соответствующего продукта, так для газа:

$$
F_{\text {sas }}{ }^{y o}=\frac{\overline{F_{c a s}(t)}}{\overline{F_{c g}}(t)}, \quad \mathrm{M}^{3} / \mathrm{m} \text {; }
$$

где $F$;aз $(t)$-мгновенное значение расхода газа, м ${ }^{3} /$ с $\left(\mathrm{m}^{3} /\right.$ ч);

$F_{c 6}(t)$ - мгновенное значение расхода сырья (свекловичной стружки, т/с (т/ч).

Аналогично рассчитываются другие оперативные показатели: удельные затраты свежей воды, электроэнергии (в случае потребления ее из городской сети) и т. п. 


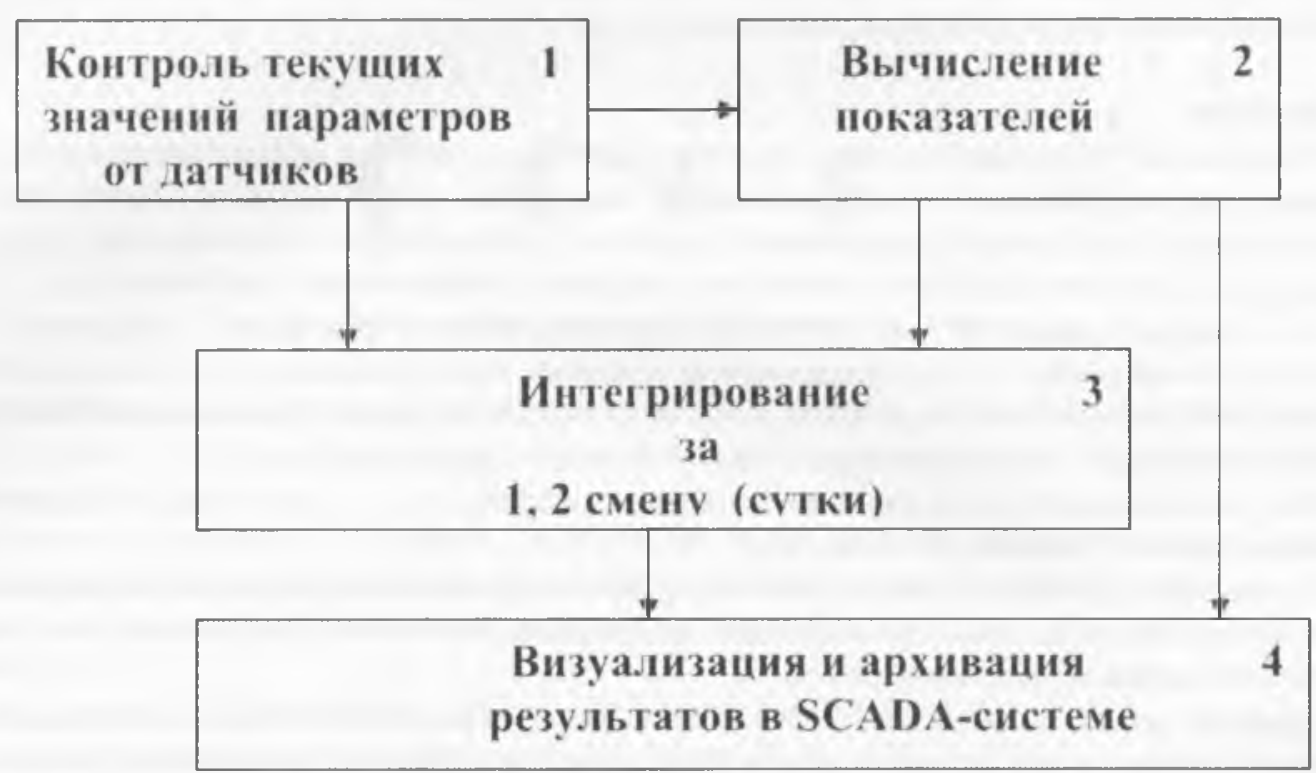

Рис.1 - Структура подсистемы оцеративного учета осиовных ТЭІІ

Все приведенные оценки архивируются и представляются пользователям в внде наборов динамических графиков за любой промежуток времени. Например, для ощенивания удельного расхода газа улобный набор : $1 \quad F_{\text {zas }}(t) ; 2 \quad F_{(\mathbf{s})}(t) ; \quad 3 \quad F_{\text {zas }}^{\text {id }}$

По согласованию со специалистами Заказчика отдельные графики удельных показателей могут быгь выведены на зкранных формах дислетчера, главного инженера, главного технолога для постоянного гредставления.

В лабораторных условиях проводилось имитационное моделирование работы подсистемы. Предлагаемая экранная форма представления результатов функционирования подсистемы представлена на рис.2. Результаты в виде динамических графиков, отражающих текущие изменения анализируемых показателей, представлены в нижней части формы, а таблица количественных показателей основных ресурсов вызывается на экран по желанию пользователя в любой момент времени.

Отдельный интерес представляет собой задача оперативного контроля и учета удельных затрат тепла передаваемых в основное производство из ТЭЦ. Удельный показатель рассчитывается аналогично предыдущим, однако, расход тепла является в условиях конкретного производства функцией ряда параметров: расхода пара, его теплосодержания (энтальпии), которое в свою очередь является функцией температуры и давления пара-передаваемого из ТЭЦ на первый корпус выпарной станции (ВС):

$$
\begin{aligned}
& F_{m}{ }^{10}=\frac{F_{m}(t)}{}, \quad \kappa \kappa a l / u^{3} \quad\left(\kappa Д ж / u^{3}\right) \text {; } \\
& \text { где FF( } \\
& F_{c}(t) \text {-лгновенный расход сока на } B C, \mathrm{M}^{3} / \mathrm{c}\left(\mathrm{u}^{3} / 4\right) \text {. }
\end{aligned}
$$




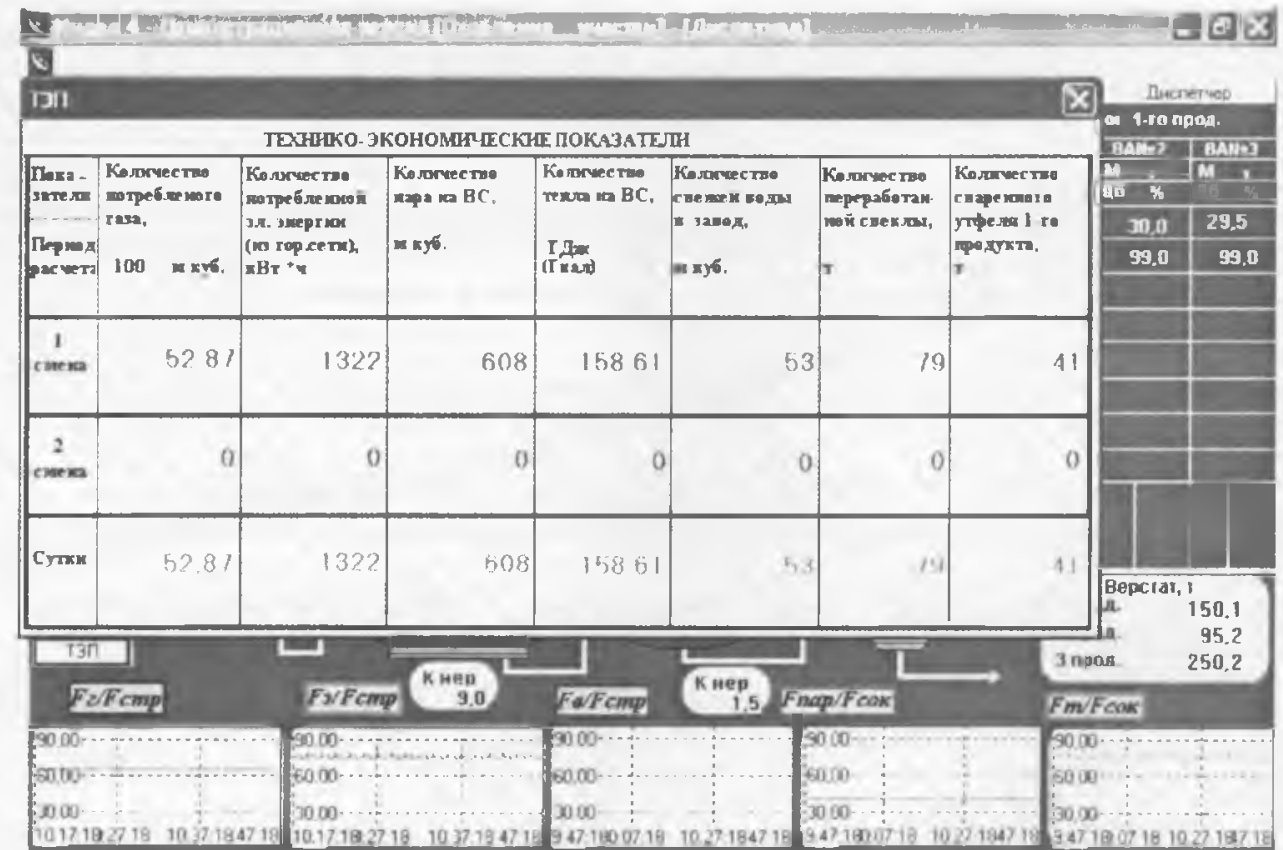

137

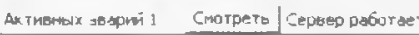

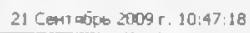

\section{Рис. 2 - Основная экранная форма главного инженера С3}

ІІредлагаемые на рынке приборные комплексы для измерения и учета расхода тепла, например счетчики пара «ИРІА» российского производства, рассчитаны на использования в системах коммерческого учета, обладают достаточной точностью, однако стоимость их весьма велика $(25$ - 40 тыс. грн). Еще более высока цена аналогичных приборов европейских производителей.

Цля рассматриваемых задач оперативного учета допустима погрешность, соизмеримая с погрешностью приборов контроля, установленных на предприятии (класс точности $1 ; 0,5$ )

Поэтому интерес представляют технические решения, обеспечивающие реализацию поставленной задачи с использованием сушествующих на предприятии вычислительных средств, либо недорогих программируемых устройств, которые можно легко встроить в действующую АСУТІ, с учетом особенностей функционируюгци программных и технических средств.

Задачи рассматриваемого класса могут быть решены как в SCADA-системе, функционирующей на рабочей станции (например, APM диспетчера, главного инженера), так и в программируемом микропроцессорном контроллере (МПК) с последующей передачей результатов в АРМ для визуализагии и архивирования.

Последнее решение является предпочтительным, поскольку вероятность бесперебойной работы контроллеров, как показывает практика эксплуатации, выше, чем компьютеров, работающих под управлением операционной системы WINDOWS в производственных условиях сахарного завода [3]

В соответствии с регламентом ведения технологического процесса производства сахара из свеклы на первый корпус ВС должен подаваться сухой насыщенный пар. Однако, исследования, проведенные в сезонах 2008-2009-2010 гт. на Староконстантиновском и Красиловском сахарных заводах Хмельницкой области показали, что пар, передаваемый на ВС, является слабоперегретым, т.е. область изменения давления $(1,1, \ldots, 2,1$ ата либо $0,1083, \ldots, 0,2059 \mathrm{MПа})$ и температуры пара $\left(\mathrm{T}=120, \ldots 135^{\circ} \mathrm{C}\right)$ позволяет определить область значений энтальпии пара над линией насыщения в соответствии IS - диаграммой и таблицей термодинамических свойств воды и водяного пара [5].

На рис. 3 приведена выделенная рабочая область на IS -диаграмме.

Таким образом, при расчетах энтальпии необходимо учитывать как факт ее зависимости от двух параметров:

$$
\begin{aligned}
i= & f(T, P), \text { ккал/кг (кіl.ж/кг) } \\
\text { где } & T-\text { температура пара, }{ }^{\circ} \mathrm{C}, \\
& P-\text { давление пара, МІІа (ата), }
\end{aligned}
$$

так и нелинейный характер этих зависимостей.

Умножив полученное значение энтальпии на мгновенное значение массового расхода пара можно получить искомое мгновенное значение расхода тепла $\mathrm{Fm}(\mathrm{t})$ 


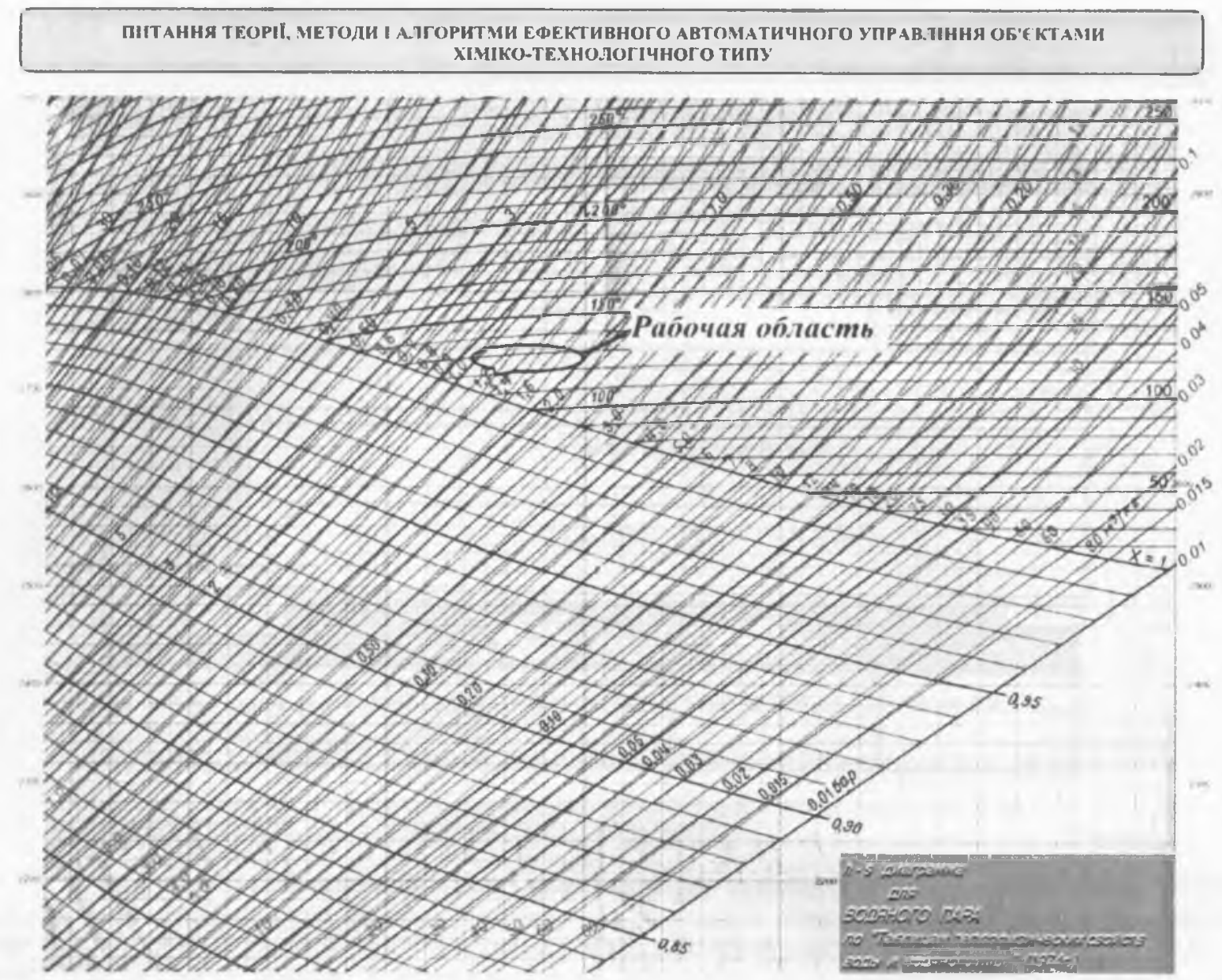

Рис. 3 - Рабочая об́ласть на диаграмме термодинамических свойств воды и водяного пара

Расчет значений энтальпии проводился с помощью компьютерной программы «1s-диаграмма», позволяюшей вычислять эти значения с высокой точностью (до четвертого знака после зашятой).

Интерфейс программы приведен на рис. 4.

Диапазон изменения исходных параметров (температура и давления пара) был разбит на интервалы по давлению $0,1-0,2$ ата $(0,01-0,02 \mathrm{MIIa})$, по температуре $-1,0{ }^{\circ} \mathrm{C}$. Такое разбиение позволяет выполиять расчеты энталыни с погрешностью не выше $0.05 \%$

Результаты расчета сведены в габлицу 1

Таким образом, полученные в табличной форме нелинейные зависимости необходимо заложить в вычислительное устройство и организовать вычислительные процедуры в реальном масштабе времени.

Выбор микропроцессорного вычислительное устройства производился с учетом реальных возможностей персонала службы главного метролога по освоению и обслуживанию подобной техники. АСУТII на этих предприятиях реализовано на базе функционально-программируемых контроллеров отечественного производства и компьютеров, оснащенных SCADA-системой «ИНДЕЛ 4», разработанной полтавским предприятием «ИНФОТЕХІІРОМ». Набор драйверов, поставляемых в комплекте со SCADA-системой, обеспечивает обмен информацией с контроллерами, как отечественного производства Ремиконт, МИК (предприятие «МИКРОЛ», Г. Ивано-Франковск), так и импортного производства (Siemens, VIPA и др.). ІІредпочтение было отдано новому программируемому контроллеру предприятия «МИКРОЛ» МИК-52, исходя из критерия стоимость - качество, с учетом близости программного обеспечения для этого контроллера (редактор «ф») к знакомому персоналу службы КИІІ и А редактору для функционируюпих на предприятии MIIK. 


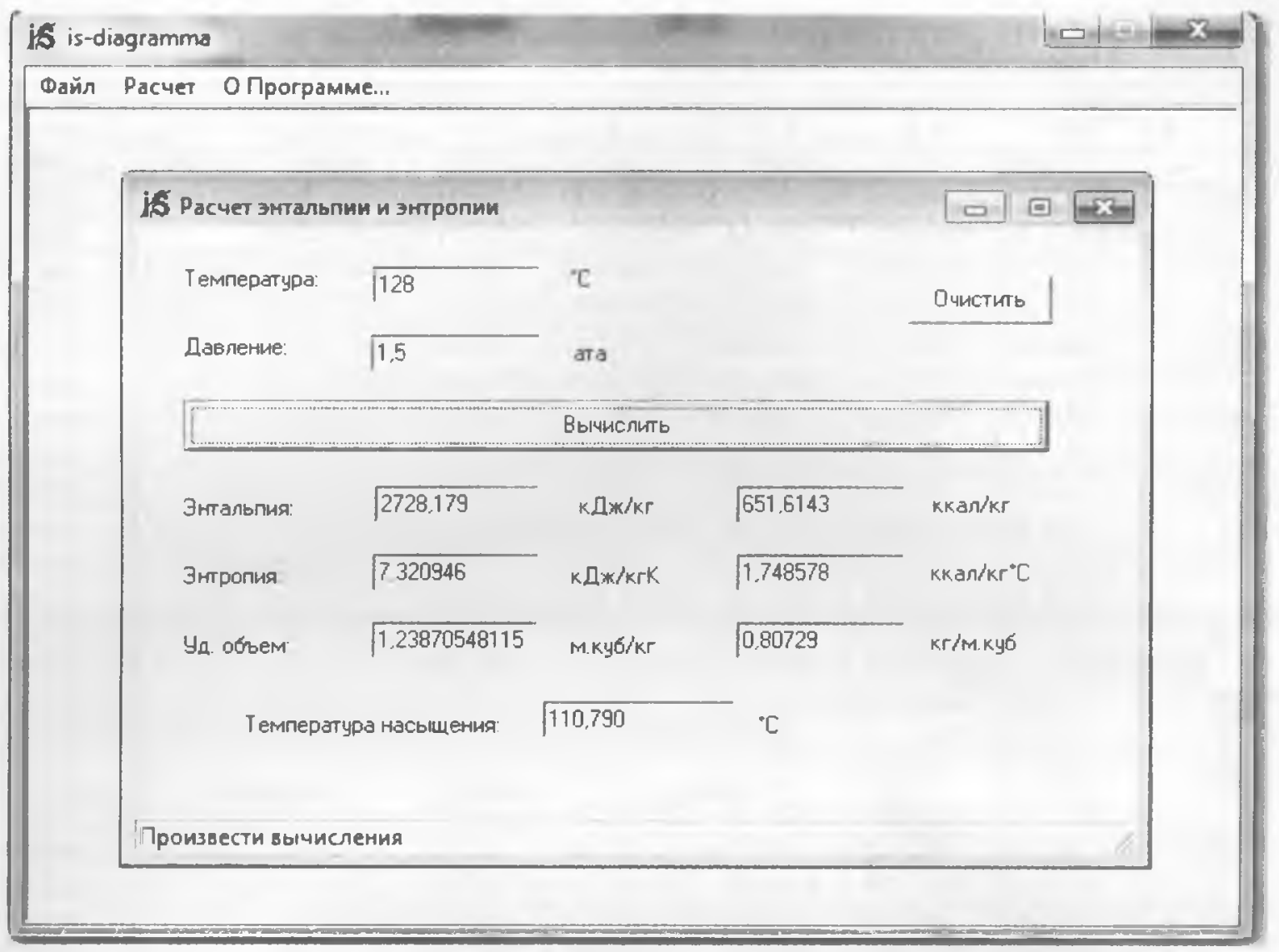

Рис. 4 - Интерфейс компьютерной прог раммы расчета знталыии

Рассматриваемая задача была решена с помощью программы, составленной в FBD-піодобнм редакторе «a» для МИК-52, приведенной на рис. 5 (включен режим отладки).

Имитационная установка, на которой проводились исследования, включала: МПК МИК-52, три аналоговых задатчика РЗД-22 (с токовым выходом 4,..,20 мА), блок преобразования интерфейсов БПИ-52, компьютер с установленным программным обеспечением: драйвер для БПИ-52, редактор «а», SCADA-система «ИНДЕЛ 4» с црайвером MODBUS, обеспечивающим обмен с MИK-52 по двухпроводному интерфейсу RS-485.

ІІоскольку в процессе исследования выяспилось "то, используемые задагыики РЗД-22 (1990 г. выпуска), при настройке на лиапазон 4,..20 мА дают на выхоле нестаб̆ильный сигнал, с помехой соизмеримой со случайными помехами в производственных условиях, было ренено не использова гь специальный генсратор случайных помех

Представленная на рис. 5 Ігрограмма содержит 21 алторитмический блок (АБ), что гримерно соответствует $25 \%$ загрузки ОЗУ МІІК. Первые три АБ типа AIN обеспечивают ввод и предварительные преобразования сигналов от датчиков давления (1), температуры (2) и массового расхода пара (3). При этом на выходе 04 (OUT_SC) AIN формируется промасштабированный сигнал в физических величинах (ата), а на выходе 05 (OUT) сигнал в процентах шкалы. АБ 4,..,11 типа LIMIT представляют собой блоюı, формирующие дискретный сигнал - признак достижения верхней границы установленного диапазона. На вход 01 этих блоков подан преобразованный сигнал давления (в \%), а с выхода 0I (dOUT_h) дискретный сигнал, поступающий в блок 12 типа IF. Диапазон изменения сигнала давления разбит на восемь поддиапазонов в соответствии с реальным диапазоном изменения параметра и табл. $1: 0-40 \%, 40-50 \%, 50-60 \%$ и т. д. Таким образом, в программе формируется признак нахождения значения давления в одном из указанных диапазонов. АБ 12 типа IF и 13 типа MUX (переключатель по номеру) работают в комплекте и позволяют при формировании в АБ 12 номера канала и передачи его в АБ 13 передавать сигнал с АБ $14, \ldots, 21$ (один из восьми) на вход 02 АБ 22, являющегося умножителем. В АБ 14,..,21 LINEAR реализована кусочно-линейная аппроксимация зависимостей энтальпии пара от температуры, соответствующих определенным значения давления (табл.1). Преобразованный сигнал температуры от АБ 2 передается всем AБ 14,..,21 LINEAR. Таким образом на вход 02 умножителя АБ 22 поступает значения энтальпии пара в соответствии с его давлением и температурой. На вход 01 этого АБ поступает преобразованный сигнал массового расхода пара (диапазон изменения $0, \ldots, 100 \mathrm{~T} /$ ) от АБ 3. На выходе АБ 22 получено искомое мгновенное значение количества тепла, передаваемого с паром на $\mathrm{BC}$. 
Таблица 1. Расчет значений энтальпии перегретого пара в раб̆очей об̈ласти ( 1 кка. $\left.1=4.18605 \kappa / 1 \% ; 1 \mathrm{~kJ} / \mathrm{ck}^{2}=0.09807 \mathrm{MIIa}\right)$

\begin{tabular}{|c|c|c|c|c|c|c|c|c|}
\hline & 1,1 & 1,3 & 1,5 & 1,7 & 1,9 & 2 & 2,1 & $\mathrm{KC} / \mathrm{CM}^{2}$ \\
\hline & 01083 & 0.1275 & 0.1471 & 0.1667 & 0.1863 & 0,1961 & 0,2059 & MПa \\
\hline \multirow[t]{2}{*}{120} & 64865 & 648,15 & 647,64 & 647,12 & 64658 & 6463104 & & $\mathrm{kkan} / \mathrm{kr}$ \\
\hline & 271576 & 2713,68 & 2711.54 & 2709.35 & 2707.111 & 2705,488 & & אД*/k \\
\hline \multirow[t]{2}{*}{121} & 649.13 & 648,64 & 648,14 & 647.63 & 647,09 & 6468301 & 3465594 & $\mathrm{kan} / \mathrm{kT}$ \\
\hline & 2717.79 & 2715,74 & 2713.63 & 2711,48 & 2709,270 & 2707,663 & 270653 & KDWKikT \\
\hline \multirow[t]{2}{*}{122} & 649.62 & 649,13 & 648,64 & 648,13 & 64761 & 6473485 & 647,082 & Kкал/KJ \\
\hline & 2719.82 & 2717.796 & 2715.72 & 2713.595 & 2711.423 & 2709833 & 2708718 & $k[\mathbb{K} / \mathrm{KT}$ \\
\hline \multirow[t]{2}{*}{123} & 650.10 & 64962 & 649.14 & 648,63 & 648,12 & 6478655 & 647,603 & KKar/kr \\
\hline & 2721,85 & 2719,851 & 271780 & 2715,711 & 713.571 & 2711.997 & 2710.899 & $\mathrm{k} Д ж / \mathrm{kT}$ \\
\hline \multirow[t]{2}{*}{124} & 650.59 & 650.11 & 649.63 & 649.14 & 648,63 & 648.3813 & 648.1228 & ккал/KT \\
\hline & 2723.88 & 2721.904 & 2719.89 & 2717,822 & 2715714 & $2714 \quad 157$ & 2713074 & $\mathrm{~K} \sqrt{[\mathrm{K} / \mathrm{K} T}$ \\
\hline \multirow[t]{2}{*}{125} & 651,07 & 650,60 & 650,13 & 649.64 & 649.14 & 648.8958 & 648.6411 & кал/kг \\
\hline & 2725,90 & 2723.954 & 272196 & 2719.930 & 2717.852 & 271631 & 2715,244 & kДж/kT \\
\hline \multirow[t]{2}{*}{126} & 651.55 & 651,09 & 650.63 & 65014 & 649.65 & 649.409 & 649.1582 & KarV/KT \\
\hline & 2727,92 & 2726,001 & 272404 & 722.033 & 2719,985 & 2718.459 & 2717,409 & [F/KT \\
\hline \multirow[t]{2}{*}{127} & 652.04 & 651.58 & 651,12 & 65064 & 650,16 & 649.9212 & 649674 & KKan/Kr \\
\hline & 2729.94 & 2728,046 & 2726.11 & 2724.133 & 2722.115 & 2720.603 & 2719,568 & кДж/k \\
\hline \multirow[t]{2}{*}{128} & 652.52 & 652,07 & 651.61 & 651,14 & 650,67 & 650.4322 & 650.1886 & KKaЛ/kr \\
\hline & 2731.95 & 2730,089 & 272818 & 2726.229 & 2724239 & 2722,742 & 2721722 & KДW \\
\hline \multirow[t]{2}{*}{129} & 652.99 & 65255 & 652,11 & 651,64 & 651,17 & 650.9421 & 650702 & $\mathrm{Kan} / \mathrm{KT}$ \\
\hline & 2733.97 & 2732.129 & 2730.25 & 2728.322 & 726,360 & 2724.876 & 2723.871 & $Д w / \mathrm{KT}$ \\
\hline \multirow[t]{2}{*}{130} & 653.48 & 65304 & 6526 & 652.14 & 651,68 & 651,451 & 651.2143 & $\mathrm{KaN} / \mathrm{kJ}$ \\
\hline & 2735.99 & 2734.167 & 2732.31 & 2730.411 & 2728.476 & 2727.007 & 2726.016 & K马+W/T \\
\hline \multirow[t]{2}{*}{131} & 653.96 & 653.53 & 653.09 & 652.64 & 652.18 & 6519588 & 551,7255 & $\mathrm{kan} / \mathrm{kT}$ \\
\hline & 2738,00 & 736,203 & 2734.39 & 2732,496 & 730.589 & 2729,132 & 2728,156 & КДж/KT \\
\hline \multirow[t]{2}{*}{132} & 654,44 & 65401 & 653,58 & 653.14 & 652.69 & 652.4656 & 652.2356 & Kan/kr \\
\hline & 2740.01 & 2738236 & 2736.43 & 2734.579 & 2732.697 & 2731254 & 2730,291 & KIf*/KT \\
\hline \multirow[t]{2}{*}{133} & 654.92 & 65450 & $654: 08$ & 65363 & 653,19 & 652,9715 & 652.7447 & KKan/Kr \\
\hline & 2742,02 & 2740,268 & 2738.48 & 2736,659 & 734.802 & 2733.371 & 2732.422 & $\mathrm{~K}[\mathrm{IN} / \mathrm{KT}$ \\
\hline \multirow[t]{2}{*}{134} & 655.40 & 654.98 & 654.56 & 654.13 & 653,69 & 6534765 & 6532528 & $\mathrm{kar} / \mathrm{kr}$ \\
\hline & 2744,03 & 2742,297 & 2740.53 & 2738,735 & 2736.904 & 2735.485 & 2734,549 & $\mathrm{~K}[\mathrm{~W} / \mathrm{KT}$ \\
\hline \multirow[t]{2}{*}{135} & 655.88 & 655.47 & 655.05 & 65463 & 654,19 & $65398 \mathrm{C} 6$ & 653.7599 & KKan $/ \mathrm{Kr}$ \\
\hline & 2746,04 & 2744,325 & 2742,58 & 2740,808 & 2739.001 & 2737,595 & 2736672 & $\kappa\left[/ *^{\prime} / \mathrm{T}\right.$ \\
\hline \multirow[t]{2}{*}{136} & 656.36 & 655.95 & 65554 & 655.12 & 65469 & 654.4838 & 654.2661 & KKan/kr \\
\hline & 2748.04 & 2746,351 & 2744,63 & 2742,879 & 2741,096 & 2739.702 & 2738.791 & $k[\$ K / K T$ \\
\hline \multirow[t]{2}{*}{137} & 656.84 & 656,43 & 656,03 & 655,61 & 655.19 & 6549861 & 654,7714 & Kкал/KT \\
\hline & 2750,04 & 2748,375 & 2746,68 & 44,947 & 743,187 & 2741,805 & 2740.906 & $k[\mathbb{f} * / k J$ \\
\hline \multirow[t]{2}{*}{138} & 657,32 & 656,92 & 656,52 & 656,11 & 655,69 & 655,4876 & 655.2757 & ккал/k \\
\hline & 2752,05 & 2750.397 & 2748.72 & 2747.012 & 2745,275 & 2743,904 & 2743,017 & kДж/к \\
\hline \multirow[t]{2}{*}{139} & 657,79 & 657.40 & 657,01 & 656.60 & 656.19 & 655,9884 & 655.7793 & kкал/kT \\
\hline & 2754,05 & 2752.418 & 2750 & 2749.075 & 2747.360 & 2746.00 & 2745.125 & $\mathrm{~K} \rrbracket \mathbb{W} / \mathrm{KT}$ \\
\hline \multirow[t]{2}{*}{140} & 658,27 & 657,88 & 657,50 & 657.09 & 656,69 & 656,4883 & 656.282 & kxar/kJ \\
\hline & 2756,05 & & 2752,80 & 2751,135 & 2749.442 & $2748,093$. & 2747,229 & $\mathrm{k} \Omega$ w/KI \\
\hline
\end{tabular}

Значение удельного расхода тепла легко получить, разделв сигнал с выхода АБ 22 на сигнал расхода сока на $\mathrm{BC}$ с помощью АБ деления DIV'

Проведенные исследования работы программы позволили оценить погрешность расчетов, которая складывается из погрешности линеаризации и погрешности, вызванной случайными помехами. Для примера приведем данные расчета относительной погрешности при температуре $\mathrm{T}=128,6{ }^{\circ} \mathrm{C}$ (среднестатистическое значение за октябрь сезона 2009-10 гг. на ВС Староконстантиновского сахзавода), и изменения давления в диапазоне 1,1, .., 2,5ата. Сравнение результатов проводилось между данными полученными в МПК и но комыютерной программе «ISдиаграммма» (базовый эталон). Данные сведены в таблицу 2 
Таб̆лица 2. Оценка огносительной пог решности расчета энтальпии пара $\left(\mathrm{T}=128,6{ }^{\circ} \mathrm{C}\right)$

\begin{tabular}{|c|c|c|c|c|c|}
\hline $\begin{array}{l}\text { Номер } \\
\text { интер- } \\
\text { ва.ла } \\
\end{array}$ & $\begin{array}{l}\text { Мгновеншое } \\
\text { значение } \\
\text { давления, ага }\end{array}$ & $\begin{array}{l}\text { Значения } i \\
\text { В МПК («(ф)), } \\
\text { Ккал/КГ }\end{array}$ & $\begin{array}{l}\text { Значения } i \\
\text { в программе (is), } \\
\text { кка.ı/кг }\end{array}$ & $\begin{array}{l}\text { Погрешность } \\
\text { расчета, } \\
\%\end{array}$ & Примечание \\
\hline 1 & 1,108 & 653,002 & 652,7886 & 0,03269 & \\
\hline 2 & 1,377 & 652,350 & 652,1899 & 0,02455 & минимальная \\
\hline 3 & 1,619 & 651,910 & 651,6368 & 0,04193 & \\
\hline 4 & 1,860 & 651.441 & 651,0724 & 0,05662 & \\
\hline 5 & 2,139 & 650,971 & 650,4020 & 0,08748 & \\
\hline 6 & 2,379 & 650,489 & 649,8108 & 0,10437 & максимальная \\
\hline 7 & 2,589 & 649,500 & 649,2830 & 0,03345 & \\
\hline
\end{tabular}

Средияя относительная погрешность по данным табл. 2 составила $0,05444 \%$, что существено меньше класса точности функцнонируюших на объекте приборов контроля параметров $(0,5, \ldots, 1,0)$. Следовательно, этот алгоритм и программа его реализации может быть предложена в составе подсистемы оперативного учета основных ТЭП АСУТП сахзавода.

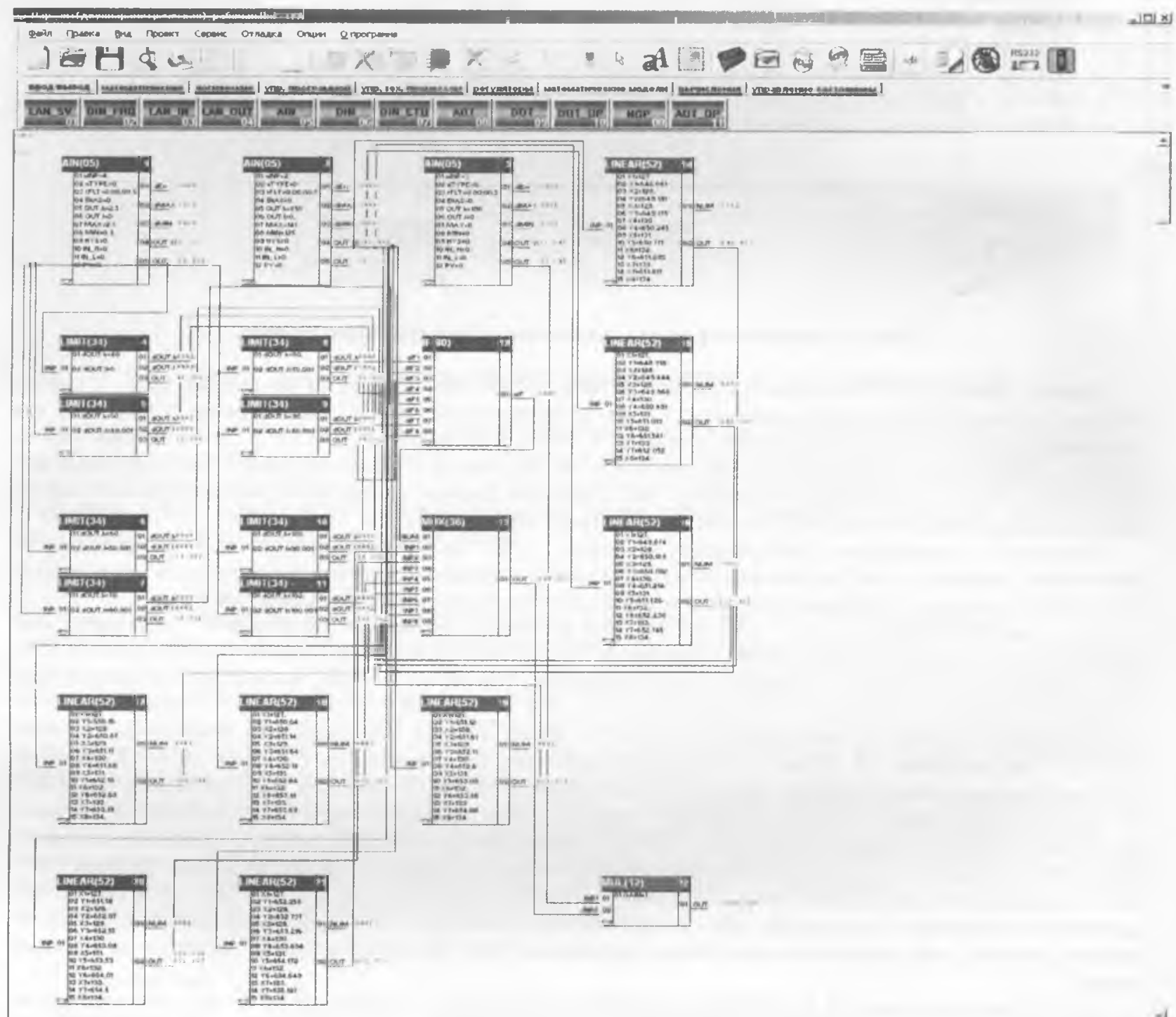

Рис. 5 - Программа рассчета энтальпии (двухпараметрическая)

Отметим, что МПК МИК-52 имеет восемь аналоговых входов, что позволяет реализовать в нем все основные вычислительные процедуры для подготовки данных и передачи их в АРМ руководителя для отображения в форме рис. 2 и архивирования. 
ІІоскольку в рассматриваемой рабочей области изменения давления и температуры слабоперегретого пара влияние давления на энтальпию существенно меньше, чем влияние темперагуры, целесообразно рассмотреть упрошенный алгоритм и программу, считая величину давления колеблещейся вблизи среднестатистического значения (по данным обследования Р-1,5 ата), и учитывать лишь нелинейную зависимость энтальпии от температуры в диапазоне $\mathrm{T}=120, \ldots, \mid 40{ }^{\circ} \mathrm{C}$ при указанном давлении.

На рис. 6 представлена программная реализация такого алгоритма, при зтом АБ । служит для формирования признака нелостоверных данных расчета в случае выхода значения давления за установленные границы. Остальные АБ работают аналогично олисанным в программе рис. 5.

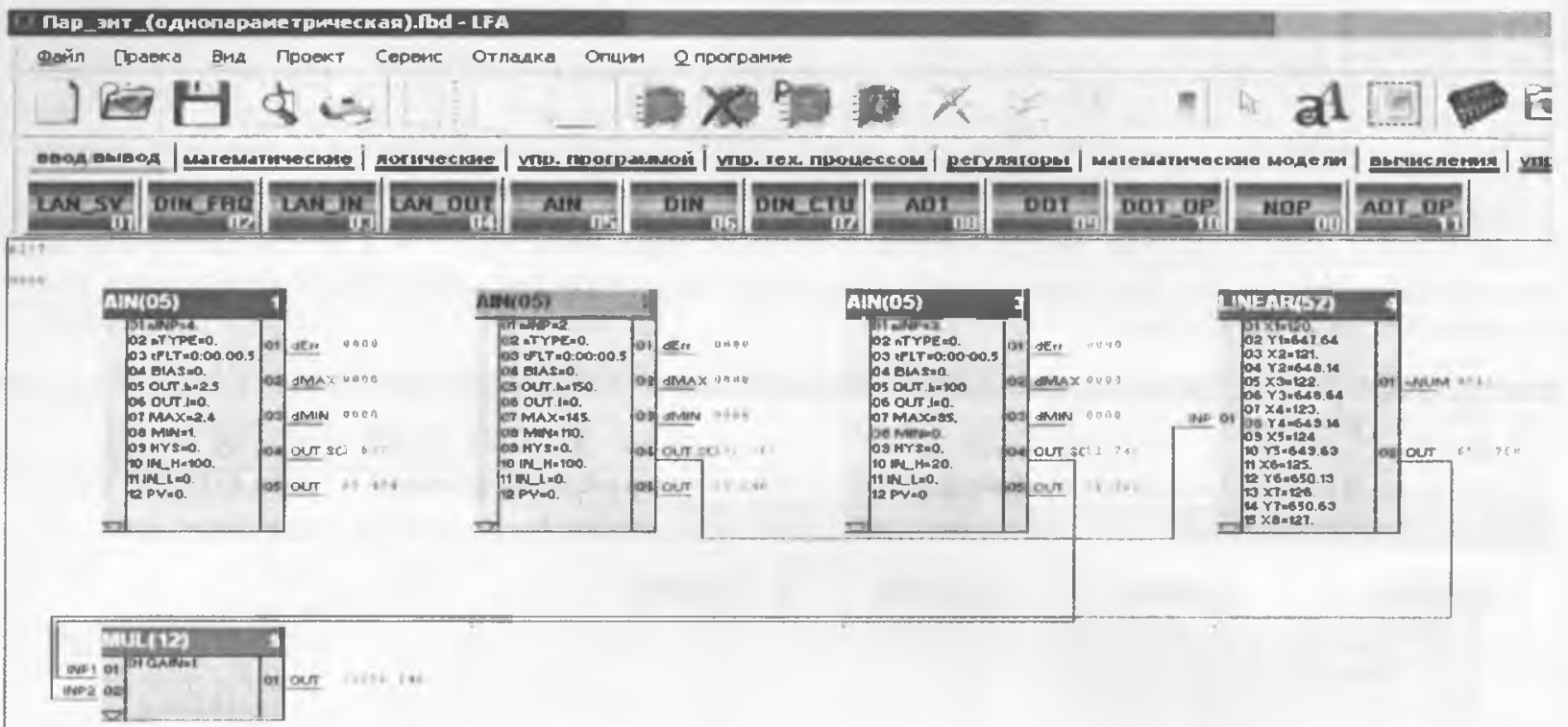

Рис. 6 - Программа расчета энтальпии (однопараметрическая)

Оценку относительной погрешности расчета в этом случае можно провести пю данным табл. 1, считая базовым значение энталыии при давлении $\mathrm{P}=1,5$ ата и температуре $\mathrm{T}=128{ }^{\circ} \mathrm{C}$. На интервале $\mathrm{P}=1,1, \ldots, 1,5$ ата максимальная относительная погрешность составила $0,1397 \%$, а на интервале $\mathrm{P}=1,5 \ldots . .2,1$ ата соответственно $0,2179 \%$. Сравнивались значения энтальпии базовое и соответствующее краям интервала изменения давления. Полученные оценки показывают возможность использования данного алгоритма в рассматриваемой задаче, поскольку результаты не используются в системах коммерческого учета.

Поскольку в подсистеме представления и учета ТЭІІ необходимо формировать и иредставлять накопленные данные за 1-ю, 2-ю смены, сутки, отражающие количество затрачиваемых ресурсов (газа, воды и т. д.), приведем на рис. 7 программу реализации такого алгоритма выполненную в редакторе «a».

АБ дискретного ввода 1 и 5 DIN служат для внешнего управления программой, позволяют при необходимости приостанавливать работу таймеров АБ 6 и 8 либо осуществлять перезапуск программы. АБ 2 $\mathrm{AIN}$ используется для ввода и предварительной обработки сигнала от датчика, например расходомера газа. Сигнал от этого АБ поступает на интеграторы АБ 3 и 7 INTEGR. В случае учета тепла АБ 2 не устанавливается, а сигнал на интеграторы поступает от блока, в котором формируются мгновенные значения расхода тепла, например АБ 22 рис. 5. Интеграторы работают под управлением таймеров АБ 6 и 8 , уставки (ТМ) которых выставляются равной; для АБ 6 - длительности смены 12 часов, для АБ 8 длительность суток 24 часа (в лабораторных условиях устанавки I мин. и 2 мин соответственно). 【ри достижении времени окончания 1-й смены на выходе таймера АБ 6 (dOUT) формируется дискретный сигнал, который останавливает работу интегратора АБ 3. ). ГІри достижении времени окончания суток (2-й смены) на выходе таймера АБ 8 (dOUT) формируется дискретный сигнал, который перезапускает всю программу. АБ 4 OR (ИЛИ) позволяет осуществлять перезапуск программы либо автоматически по таймеру АБ 8, либо от внешнего дискретного сигнала (кнопкой, при первоначалыном запуске программы либо для синхронизации таймера с заводскими часами),

На выходе интегратора АБ 3 получено накопленное за 1-ю смену, а на выходе АБ 7 - за сутки, количество затраченного ресурса (газа, тепла и т. д.). Аналогичные данные за 2-ю смену получают на выходе сумматора АБ 9, где вычисляют разницу между суточным и сменным (1-я смена) значением показателя.

Для окончательного представления данных в динамическую отчетную форму рис. 2, полученные результаты масштабируются либо с помошью уставки интегратора, либо в АБ 2, либо непосредственно в SCADA-системе. 


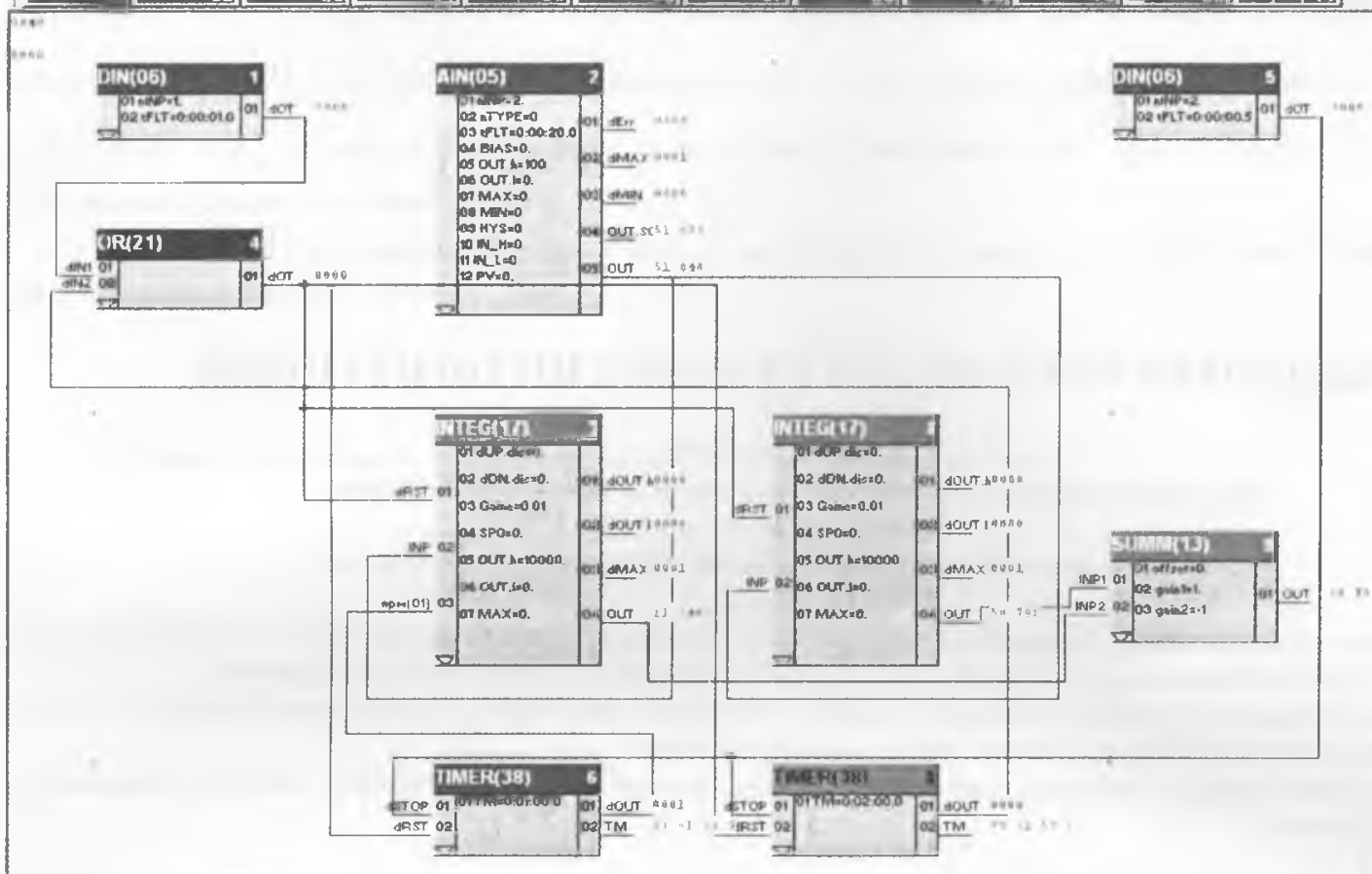

Рис. 7 - Программа оперативного учета параметров за 1-ю, 2-ю смены, сутки

Таким образом, все дополнительные данные, необходимые для представления в экранной форме рис. 2 могут быть получены в одном МПК МИК-52, учитывая, что ряд показателей: количество сваренного утфеля, количество прерабоганной свеклы и др. [3], рассчитываются на функционирующих в составе АСУТП АРМах операторов диффузионного и продуктового отделений, можно оценить вычислительный ресурс МИК-52, как достаточный для реализации поставленной задачи.

\section{Выводы}

В составе современных систем автоматизации сахзаводов класса АСУТІ, строящихся на базе микропроцессорных контроллеров, персональных компьютеров, локальных сетей, может быть реализована подсистема оперативного контроля и учета основных технико-экономических показателей работы завода, позволяющая на основе представляемых на АРМах технических руководителей данных для оперативного контроля, анализа и своевременного принятия решений по управлению технологическими процессами свеклосахарного производства (корректировки режимов, производительности и т. п.) повысить эффективность работы завода и снизить удельные затраты сырья и энергоресурсов.

Предложенные на основе результатов проведенных исследований технические решения позволяют создавать рассматриваемые подсистемы на базе отечественных технических и программных средств с минимальными затратами на комплектующие. Эти решения будут предложены ряду предприятий, где уже функционируют системы класса АСУТІІ (Староконстантиновский, Красиловский сахзаводы), а также использованы при создании новых систем подобного класса.

\section{Литература}

1. Жуковский Э.И., Скаковский Ю.М., Витвицкий В.Д., ІІайкова О.П., Бабков А.В. Основные направления развития АСУТП свеклосахарного производства//Автоматизация технологических и бизнес-процессов. Одесса: 2010 - №1 - С. 30-36.

2. Вітвицький В.Д., Скаковський Ю.М. Рішення задач оцінювання якості управління в АСУТП ділянок цукробурякового виробництва //Наук. пр. Одес. нац. акад. харч. техн./ Міністерство освіти і науки України. - Одеса: 2003 - Вип. 25.- С.130-137. 
3. Вітвицький В.Д., Скаковський Ю.М. Рішення задач оперативного обліку в АСУТІІ ділянок цукробурякового виробництва // Наук. пр. Одес. нац. акад. харч. гехн./ Міністерство освіти і науки України. - Одеса: 2004 -Вип. 27.- С.213-221.

4. Жуковский Э.И., Скаковский Ю.М., Витвицкий В.Д. Современные тенденции и перспективы автоматизации сахарных заводов //Автоматика-2008: доклады XV международной конференции по автоматическому управлению. 23-26 сентября 2008 г., т.1. - Одесса: ОНМА. - С. 197-200.

5. Вуколович М П. Термодинамические свойства воды и водяного пара. Таблицы и диаграммы. -M: Машгиз, $1951.94 \mathrm{c}$.

УДК 621.319 .7

\title{
РОТОРНАЯ МОДЕЛЬ ЭЛЕКТРОМАГНИТНОГО ПОЛЯ
}

\author{
Монтик П.Н., проф. \\ Одесская национальная академия пищевых технологий, Одесса, \\ Гамолич В.Я, ст. н. с. \\ Одесский национальный политехнический университет, Одесса.
}

Рассиотрен нетод создания этектромагнитных nотеі, амплитуды напряженности и частоты которых определяются, соответственно, геометрическої фориой электрода и скоростью его враијения.

The method of creation of the electromagnetic fields is considered, amplitudes of tension and frequency of which concerne, by the geometrical form of electrode and speed of his rotation.

Ключевые слюва: заряд, потенциал, электрическое поле, амплитуда, напряжённость, частота, декартовы и полярные координаты.

В экспериментальных исследованиях, математическом моделировании процессов в электромеханических системах, в электротехнологических установках для элетросепарации и транспортирования дисперсных материалов, нанесения порошковых покрытий, электроплазмолиза, электроантисептирования и в других областях промышлености широко применяются различные по структуре энергетические поля. Они интенсифицируют технологические процессы и, соответственно, позволяют улучшить качественные показатели продукции при снижении энергозатрат [2,3,4]

Эффективность использования энергетических полей во многом определяется физическими характеристиками исходных продуктов, которые складываются, в свою очередь, из комплекса их физикохимических свойств. С учетом непрерывности спектра электромагнитных полей, следует учитывать их действующие факторы, например, напряженность, частоту, форму (круговое, импульсное и т.д.) полей. ІІрактическая реализация такихустройств, обеспечивающих создание вращающихся полей с требуемыми параметрами, в литературе освещены недостаточно полно [1,2,4]. ІІоэтому ниже рассматривается метод создания электромагнитных полей с наперед заданным законом распределения напряженности $\bar{E}(r, \varphi, Z$, t) Такие поля предполагается получать путем вращения заряженного одного или нескольких электродов определенной формы, расположенные на поверхности ротора, выполненного в виде диэлектрического цилиндра.

Теоретической базой этого метода является уравнение Пуассона, согласно которому потенциал поля $\mathrm{U}(\mathrm{r}$, $(\varphi, Z)$ определяется следуюшим уравнением:

$$
\Delta \mathbf{u}=-\rho / \varepsilon \varepsilon_{0}
$$

где: $\rho$ - плотность распределения зарядов в системе электродов;

$\varepsilon_{0}$ - электрическая постоянная;

$\varepsilon$ - относительная диэлектрическая проницаемость среды;

$\rho, \varphi, \mathrm{Z}$ - цилиндрические координаты.

Уравнение (1) может быть приведено к двухмерному виду, если рассматривать условия создания кругового вращающегося электрического поля. В общем случае краевые условия для уравнения (1) записываются в виде зависимостей между градиентом потенциала и напряженностью поля. 